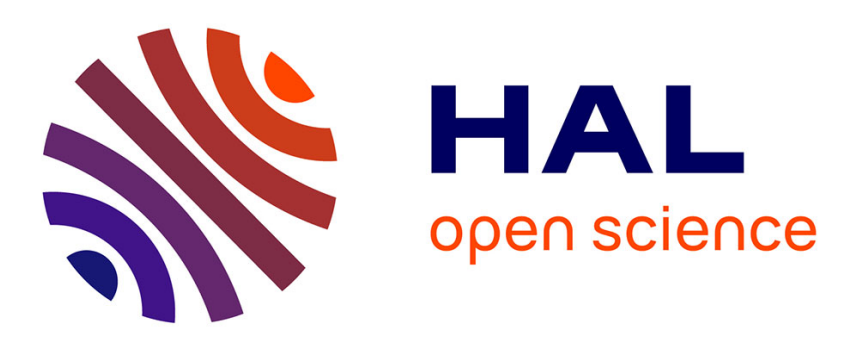

\title{
An investigation of the fine structure of the Al-K and Ti-K edges in intermetallic compounds using electron microscopy and synchrotron radiation
}

\author{
G. Blanche, M. Jaouen, A.-M. Flank, G. Hug
}

\section{- To cite this version:}

G. Blanche, M. Jaouen, A.-M. Flank, G. Hug. An investigation of the fine structure of the Al-K and Ti-K edges in intermetallic compounds using electron microscopy and synchrotron radiation. Journal de Physique IV Proceedings, 1994, 04 (C9), pp.C9-145-C9-150. 10.1051/jp4:1994922 • jpa-00253483

HAL Id: jpa-00253483

https://hal.science/jpa-00253483

Submitted on 1 Jan 1994

HAL is a multi-disciplinary open access archive for the deposit and dissemination of scientific research documents, whether they are published or not. The documents may come from teaching and research institutions in France or abroad, or from public or private research centers.
L'archive ouverte pluridisciplinaire HAL, est destinée au dépôt et à la diffusion de documents scientifiques de niveau recherche, publiés ou non, émanant des établissements d'enseignement et de recherche français ou étrangers, des laboratoires publics ou privés. 


\title{
An investigation of the fine structure of the Al-K and Ti-K edges in intermetallic compounds using electron microscopy and synchrotron radiation
}

\author{
G. Blanche, M. Jaouen*, A.-M. Flank** and G. Hug \\ Laboratoire d'Etude des Microstructures, ONERA-CNRS, BP. 72, 92322 Châtillon, France \\ * Laboratoire de Métallurgie de Physique, UA 131 du CNRS, 40 av. du Recteur Pineau, 86022 Poitiers, \\ France \\ ** Laboratoire pour l'Utilisation du Rayonnement Electromagnétique, CNRS-CEA-MEN, Centre \\ Universitaire Paris Sud, Campus d'Orsay, Bât 209D, 91405 Orsay cedex, France
}

\begin{abstract}
- Abstract
The extended fine structures of the aluminium and titanium K-edges of metals and intermetallics of the $\mathrm{Ti}-\mathrm{Al}$ phase diagram are studied using both $\mathrm{X}$-ray Absorption Spectrometry (XAS) and Electron Energy Loss Spectrometry (EELS). The Extended X-ray Absorption Fine Structure (EXAFS) and EXtended Electron Energy Loss Fine Structure (EXEELFS) in TiAl due to the first coordination shell are isolated and quantified using the standard method. For more accuracy, the phase and amplitude of backscattering are derived from the experimental measurements in pure metals $(\mathrm{Al}, \mathrm{Ti})$ and line compounds $\left(\mathrm{Al}_{3} \mathrm{Ti}\right.$, $\mathrm{Ti}_{3} \mathrm{Al}$ ). Results from EXAFS and EXEELFS are in very good agreement. The analyzed volumes can be up to $10^{7}$ time smaller with electrons, allowing the study of precipitates.
\end{abstract}

\section{INTRODUCTION}

Several intermetallic alloys are currently under investigation for use at high temperature and high stress in the aerospace industry. They are generally formed by the association of aluminium, which provides lightness, and one transition metal. These materials are qualified as "ordered" since they result in the ordering of the metallic atoms on a host simple lattice (fcc, hcp, bcc...). Typical examples are NiAl, $\mathrm{Ni}_{3} \mathrm{Al}, \mathrm{Fe}_{3} \mathrm{Al}$ or TiAl which is probably one of the more promising candidates in regard of its combination of good properties. It must also be noticed that practical metallurgical materials are always complex and multiphased, and contain several minor additions. There is nowadays a considerable effort in the scientific community to understand the fundamental aspects of the physical and mechanical properties of these compounds from first principles. Yet, different teams [1,2] have performed band structure calculations with an attempt to provide $a b$ initio calculations of defects participating in deformation mechanisms. In this context, a lot of accurate local information is required to predict the behavior of real materials. The study of fine structures of absorption edges can provide very useful information such as : crystallographic structures, ordering, Debye-Waller factor or effect of alloying [3]. However, from the above reasons one can see that two conditions are required. The first one is that small volumes of material must be probed in order to be able to distinguish between different phases. This is well realized by EELS. The second one is that an access to K-edges of transition metals is desirable. EXAFS can be routinely used for these elements. In the case of EXEELFS, however, only the information in a range between 0 to $2 \mathrm{keV}$ is generally used, due to the strong decrease in the scattering cross section with energy loss. Work on $\mathrm{L}_{23}$ of these elements has also been done $[3,4]$, however, in this case, the overlaps arising from the number of initial-final states impede a straightforward quantification. Therefore, most experiments involving $\mathrm{K}$-edges have up to now concentrated on elements between $\mathrm{B}$ and $\mathrm{Si}$ [5]. In this work we report 
the possibility of working out EXEELFS oscillations on the K-shell of transition metals (up to $\mathrm{Cr}-\mathrm{K}$ ) in intermetallic compounds.

\section{EXPERIMENTAL PROCEDURE}

The alloys $\left(\mathrm{Al}_{3} \mathrm{Ti}, \mathrm{Ti}_{3} \mathrm{Al}, \mathrm{Ti}_{48} \mathrm{Al}_{52}, \mathrm{Ti}_{46} \mathrm{Al}_{54}\right)$ have been processed from high purity metals by arc melting under argon atmosphere. The alloys are then heat treated at $1300^{\circ} \mathrm{C}$ for 48 hours for homogenization, quenched and then heat treated again at $1000^{\circ} \mathrm{C}, 100$ hours for stabilization. Thin foils for electron microscopy have been made by conventional electro-polishing methods. They are observed in a Jeol 4000FX microscope operating at $400 \mathrm{kV}$ fitted with a Gatan model 666 parallel detection electron spectrometer. The experiments were performed with a holder cooled down to $108 \mathrm{~K}$ in order to avoid contamination and to minimize thermal vibrations. Spectra are recorded in the diffraction mode with a low convergence incident beam $(\leq 1.5 \mathrm{mrad})$ and a collection semi-angle of approximately $3 \mathrm{mrad}$. XAS spectra were recorded at LURE at $77 \mathrm{~K}$ using the synchrotron radiation emitted from the DCI (Ti-K : $\mathrm{Si}[311]$ monochromator on beam line D13) and Super-ACO (Al-K : quartz [100] monochromator on beam line SA32) storage rings. Typical spectra were acquired in the electron conversion mode (CEEXAFS) on intermetallics, since their brittleness prevents the obtention of thin uniform foils. Spectra on metals were recorded in the transmission mode with typical sample thickness of $15 \mu \mathrm{m}(\mathrm{Al}, \mathrm{Ti})$.

\section{SIGNAL ANALYSIS}

EELS Spectra need to be corrected in two steps. The first one consists of correcting the intrinsic defects of the detector (a photo-diode array) by subtracting the dark current counts from the spectra and dividing them by a function which represents the channel-to-channel gain variation. The second step originates more directly from the physical interaction of the fast electrons with the samples. It consists of removing the effect of plural scattering by a standard deconvolution procedure. Even though the thickness of the specimen was smaller than the mean free path $(\mathrm{mfp})$ of the fast electron and we work with rather high accelerating voltages $(400 \mathrm{keV})$, we have found that it is absolutely necessary to perform this step. The EXAFS/EXEELFS signals are then analyzed through the standard procedure as available from the software package developed by Michalowicz [6] and has been described in a previous paper [7] and is not repeated herein.

\section{RESULTS}

\subsection{Pure metals : Al, Ti, V, Cr}

The extended fine structures $\chi(\mathrm{k})$, of the $\mathrm{Al}-\mathrm{K}, \mathrm{Ti}-\mathrm{K}, \mathrm{V}-\mathrm{K}$ and $\mathrm{Cr}-\mathrm{K}$ edges are shown in figure 1 . In case of aluminium and titanium the X-ray absorption and EELS data are superimposed (fig. 1.a \& 1.b) whereas only EELS experiments have been performed for $\mathrm{V}-\mathrm{K}$ (fig. 1.c) and $\mathrm{Cr}-\mathrm{K}$ (fig. 1.d). It can be clearly seen

(a)

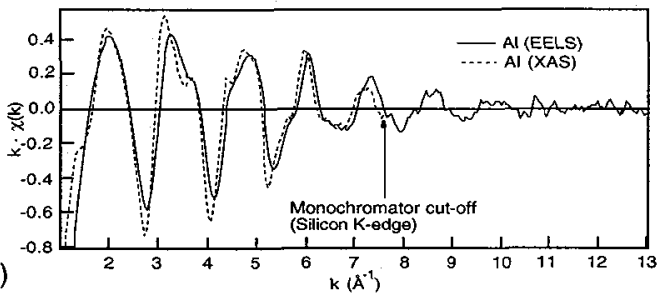

(b)

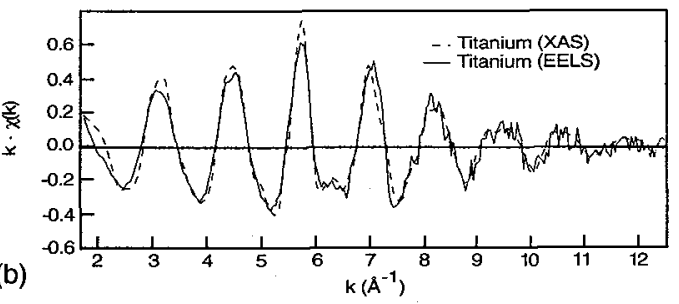

(c)

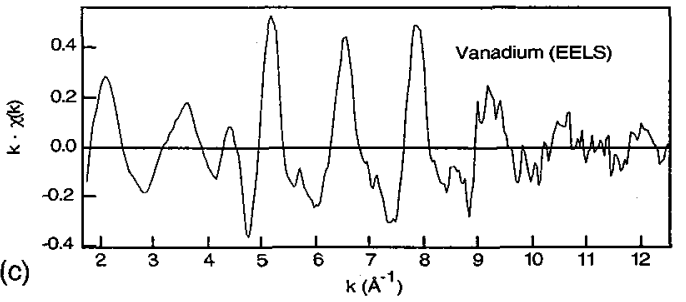

(d)

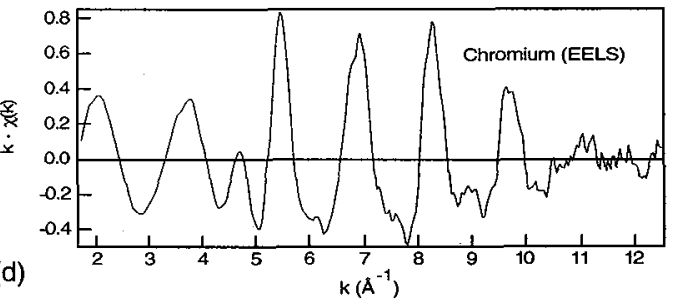

Figure 1: $\chi(k):(a) \&(b) A l \& T i$ EELS (solid) XAS (dashed); (c) \& (d) V\& Cr EELS. 

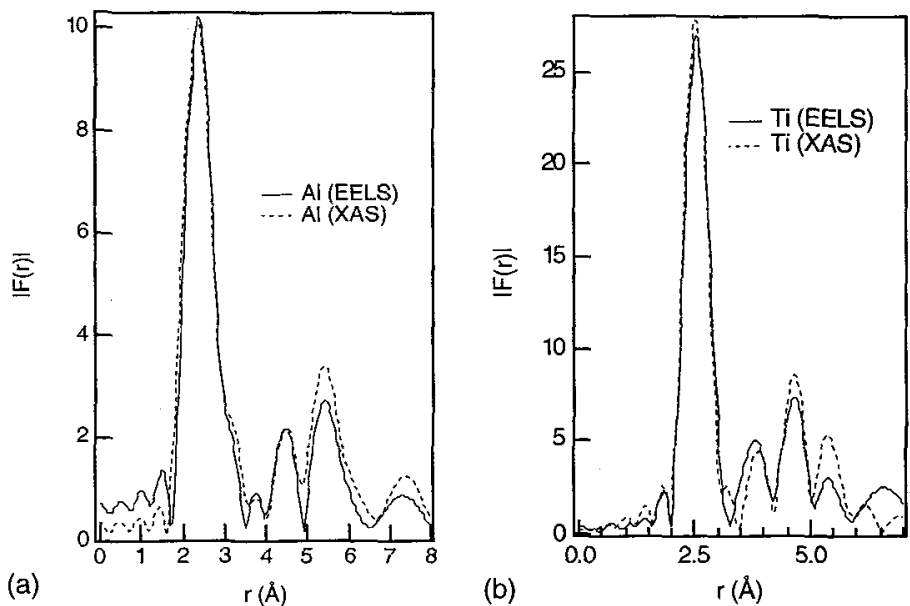

(b) $r(\AA)$
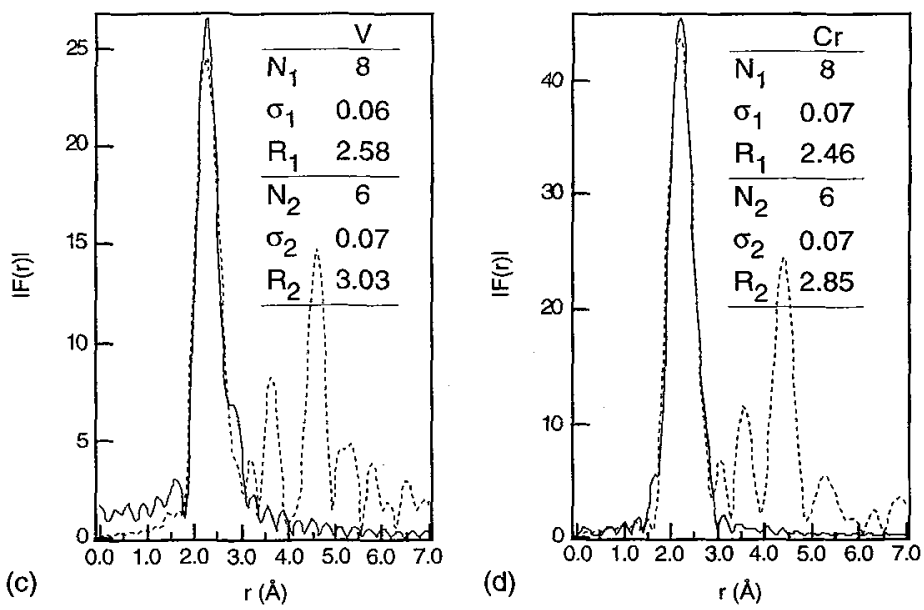

Figure 2: RDFs : (a) \& (b) Al \& Ti EELS (solid) XAS (dashed); (c) $\&(d) V \& C r E E L S$ (dashed) with first and second shell simulation (solid).

from fig. 1.a that the aluminium $\chi(k)$ is cut off at $7.6 \AA^{-1}$ which actually corresponds to the position of the silicon K-edge of the monochromator. The EELS data do not suffer this limitation, resulting in potentially much better resolution in real space. For each metal the first peak in the RDF (fig. 2) has been extracted and fitted with the phase shifts and amplitudes as deduced from the McKale procedure [8]. Although titanium shows a slight deviation from the perfect hexagonal close packing $(\mathrm{c} / \mathrm{a}=1.588)$ only one mean distance has been used for modeling the first shell peak. In the case of bcc metals ( $\mathrm{Cr}$ and $\mathrm{V})$, however, the first peak in the RDF contains the signal from the two first shells, and is modelled consequently. The results of the fit and the RDFs together with the simulation of the first peak are presented in fig. 2.c and 2.d. Finally, instead of the fitting procedure, experimental phase-shifts and backscattering amplitudes have been deduced from our data for the study of intermetallic compounds.

\subsection{Standards $\mathrm{Al}_{3} \mathrm{Ti}$ and $\mathrm{Ti}_{3} \mathrm{Al}$}

At the $\mathrm{A}_{3} \mathrm{~B}$ composition two compounds exist in the $\mathrm{Ti}-\mathrm{Al}$ phase diagram : $\mathrm{Ti}_{3} \mathrm{Al}$ and $\mathrm{Al}_{3} \mathrm{Ti}$ which are ordered superstructures of the hcp lattice $\left(\mathrm{DO}_{19}\right)$ and the fcc lattice $\left(\mathrm{DO}_{22}\right)$, respectively. The key point is that, if one considers the minor component ( $\mathrm{Ti}$ in $\mathrm{Al}_{3} \mathrm{Ti}$ or $\mathrm{Al}$ in $\mathrm{Ti}_{3} \mathrm{Al}$ ), in each case it is surrounded by twelve first nearest neighbor $(1 \mathrm{nn})$ atoms of the opposite kind. Therefore, after recording the $\chi(\mathrm{k})$ 

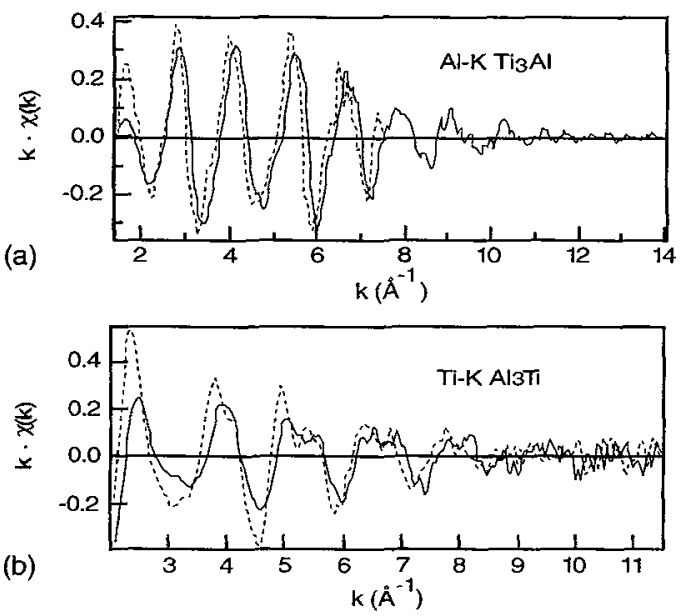

Figure 3: $\chi(k)$. (Solid: EELS; dashed XAS). (a) $A l-K\left(T i_{3} A l\right)$ and $(b) T i-K\left(A l_{3} T i\right)$.
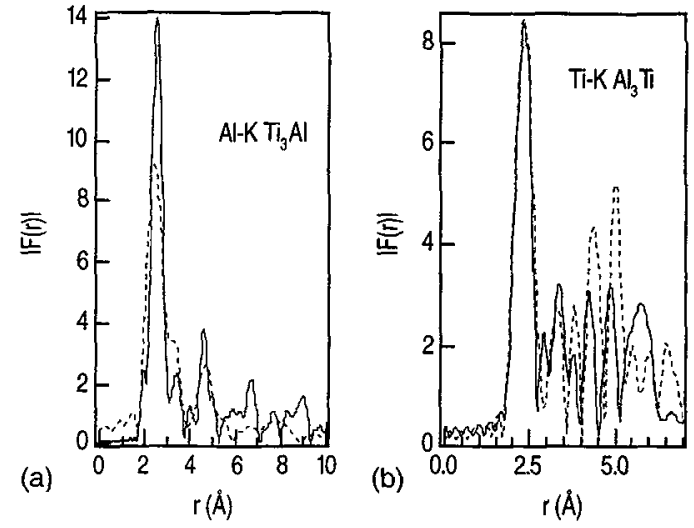

Figure $4:$ RDFs (Solid: EELS ; dashed XAS) : (a) $A l-K$ in $T_{3} A l$ note the better resolution in EELS due to the larger window in $k$ for the Fourier Transform; (b) $\mathrm{Ti}-\mathrm{K}$ in $\mathrm{Al}_{3} \mathrm{Ti}$.

function of the minor element (fig. 3) it has been possible to extract experimental phases and backscattering amplitudes for both Ti-Al and Al-Ti pairs from the corresponding RDF (fig. 4). For this purpose the $1 \mathrm{nn}$ distances were calculated from electron diffraction measurements recorded at the same temperature as the EELS experiments (108 K).

\subsection{Results on TiAl}

The intermetallic compound $\mathrm{TiAl}$ has the well-known $\mathrm{LI}_{0}$ structure of $\mathrm{CuAu}$ which results from an ordering of the atoms on the fcc lattice. It consists of alternate planes of titanium and aluminum along the c axis and, consequently, the first shell around an atom of titanium (resp. Al) is composed of 8 aluminium and 4 titanium atoms (resp. $8 \mathrm{Ti}$ and $4 \mathrm{Al}$ ). The comparison of the $\chi(\mathbf{k})$ of TiAl recorded by EELS and $\mathrm{XAS}$ on the Ti-K edge of TiAl is presented in fig. 5. Their Fourier transforms have been performed over a window in $\mathrm{k}$ ranging from 3 to $14 \AA^{-1}$. When this large window is used, two peaks are clearly resolved at 2.4 and $2.6 \AA$ in the radial distribution function (fig. 6). These two peaks have been identified as resulting from the titanium and aluminium atoms of the first shell (i. e. nearly the same actual distance), the separation being due to the different phase shifts associated with each atom species. The filtered backtransformed spectrum oscillating $\chi(\mathrm{k})$ has been successfully fitted assuming a number of $1 \mathrm{nn}$ consistent with the stoichiometry (table A). This procedure has been done using the experimental

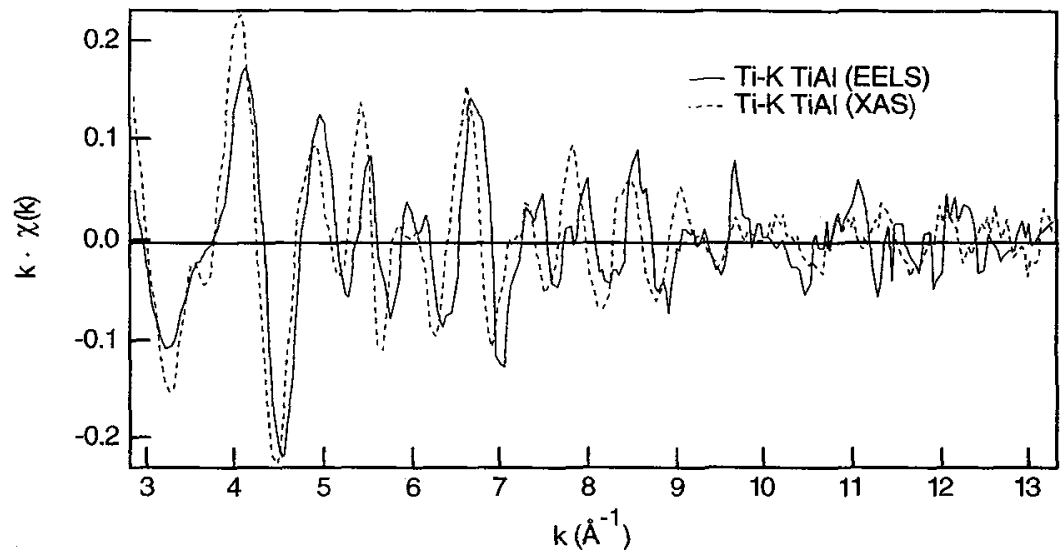

Figure $5: \chi(k)$ of TiAl; EELS (solid) and XAS (dashed). 


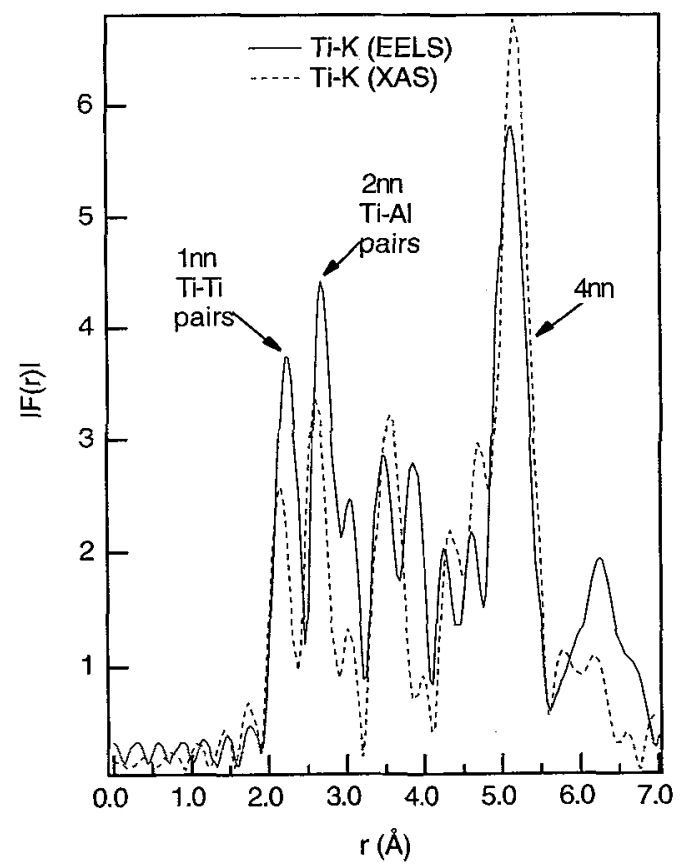

Figure $6: R D F$ of TiAl; EELS (solid) and XAS (dashed).

Table A

Results of the fits of $T i-K$ in $T i_{48} A l_{52^{*}}$ (EELS data)

\begin{tabular}{lccc|ccc} 
& \multicolumn{3}{c|}{ Ti-Ti pairs } & \multicolumn{3}{c}{ Ti-Al pairs } \\
& $\mathrm{N}_{1}$ & $\sigma_{1}$ & $\mathrm{R}_{1}$ & $\mathrm{~N}_{2}$ & $\sigma_{2}$ & $\mathrm{R}_{2}$ \\
\hline Cryst. data & 3.84 & & 2.81 & 8.16 & & 2.83 \\
Fit McKale & 3.8 & 0.06 & 2.85 & 8.2 & 0.066 & 2.87 \\
Fit exp. ph. \& ampl. & 3.8 & 0.02 & 2.85 & 8.2 & 0.03 & 2.87 \\
\hline
\end{tabular}

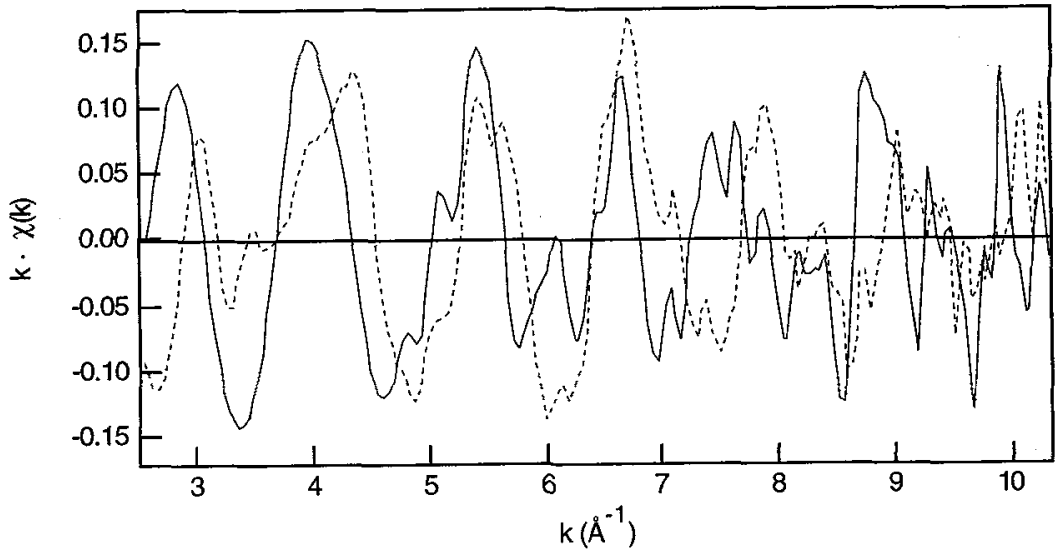

Figure 8: Comparaison of the $\chi(k)$ of the Al-K edge in TiAl (dashed line) and in the H-phase(solid line). 
backscattering amplitudes and phase shifts deduced from the above studies. Another feature of interest on the RDF is the strong peak at approximately $5.1 \AA$. It corresponds to the fourth neighbors $(4 \mathrm{nn})$ which are aligned in the fcc lattice with the first neighbors $(1 / 2<110>$ and $<110>$ distances). Therefore its high magnitude should be most probably interpreted as a strong focussing effect of the $1 \mathrm{nn}$ onto the $4 \mathrm{nn}$.

\subsection{Results on precipitates}

The usefulness of the EXEELFS analysis is exemplified in fig. 8 , which shows the $\chi(\mathrm{k})$ deduced from the Al-K edge of an oxide precipitate (H-phase) in TiAl of composition $\mathrm{Ti}_{2} \mathrm{AlO}_{\mathrm{x}}$. It is compared with the corresponding signal of the TiAl matrix. The exact crystallographic structure of this phase is not completely known [9]. A strong modification of the oscillations at low $\mathbf{k}$ values comes from the presence of oxygen atoms which are strong backscatterers in this k-range. It is also evidenced by a peak at $2 \AA$ clearly visible in the RDF (fig. 9) coming from the presence of $\mathrm{O}$ atoms as close neighbors of the $\mathrm{Al}$ atoms. No fit has been attempted so far, it will be presented

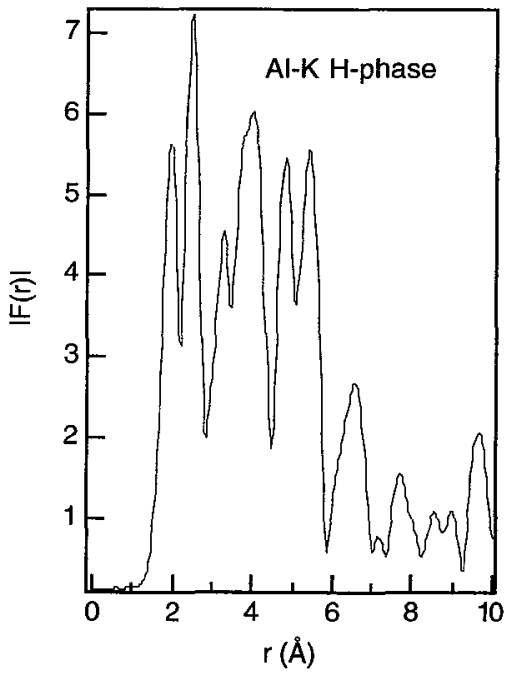

Figure 9 :RDF of Al-K in $H$-phase in a forthcoming paper dedicated to the analysis of these precipitates. The size of the precipitate is $300 \mathrm{~nm}$ in diameter and $30 \mathrm{~nm}$ in thickness.

\section{DISCUSSION AND CONCLUSION}

Extended fine structures of absorption $\mathrm{K}$-edges in the 2-6 keV energy range have been successfully recorded by electron energy loss spectrometry and quantified. The agreement with XAFS experiment can be very good. The typical analyzed volume are $2 \cdot 10^{8} \mu \mathrm{m}^{3}$ in EXAFS or $0.3 \mu \mathrm{m}^{3}$ in EXEELFS [7]. It is limited with the latter technique when the magnitude of the $\chi(\mathrm{k})$ falls below the intrinsic noise of the detector. In the case of the above precipitate the volume analyzed was estimated at about $8.510^{-3} \mu \mathrm{m}^{3}$. This value can, be easily improved with an increase in beam brightness using an electron microscope fitted with a field emission gun and with detectors of lower intrinsic noise than photo-diode arrays (CCDs).

\section{- References}

[1]. Fu C. L. and Yoo M. H., Phil. Mag. Lett., 62 (1990) 159-165.

[2]. Woodward C., MacLaren J. M. and Dimiduk D. M., Mat. Res. Symp. Proc. 228 (1993) 171-176.

[3]. Okomoto J. K., Pearson D. H., Ahn C. C. and Fultz B., EELS analysis of the Electronic Structure and Microstructure of Metals, New Orleans February 171991 (TMS 1992) pp. 183-216.

[4]. Okomoto J. K., Ahn C. C. and Fultz B., Microbeam Analysis (1991) 273-277.

[5]. Serin V., Zanchi G. and Sévely J., Microsc. Microanal. Microstruct. 3 (1992) 201.

[6]. Michalowicz A., EXAFS pour le Mac, in : Logiciels pour la Chimie (Soc. Fr. Chimie, Paris, 1991) p 102.

[7]. Blanche G., Hug G., Jaouen M. and Flank A.-M., Ultramic. 50 (1993) 141-145.

[8]. McKale A. G., J. Am. Chem. Soc. 110 (1988) 3763.

[9]. Hug G. unpublished work, Technical report \# RT28/7228M available from ONERA (1992). 